\title{
Water fluoride concentration and fracture of the proximal femur
}

\author{
C Cooper, C Wickham, R F Lacey, D J P Barker
}

\begin{abstract}
Study objective-The aim of the study was to examine the relationship between water fluoride concentration and the incidence of hip fracture, since evidence on this is at present inconsistent.

Design-Numbers of hospital admissions for fractures of proximal femur were obtained from hospital activity analysis data for the years 1978-1982. The fracture rates were compared with water fluoride concentrations in 39 county districts of England and Wales (fluoride concentrations had been measured in these districts between 1969 and 1973 as part of the British Regional Heart Study).

Patients-During the study period, 4121 men and 16272 women aged 45 years and over were discharged from hospital after hip fracture.

Results-Poor correlations were found between discharge rates and both total $(r=0.16, p=0.34)$ and natural $(r=0.01$, $p=0.95$ ) water fluoride concentrations.

Conclusions - Water fluoridation to levels of around $1 \mathrm{mg} / \mathrm{litre}$ is unlikely to reduce hip fracture incidence markedly in this country.
\end{abstract}

Osteoporosis is an important risk factor for hip fractures in the elderly. ${ }^{1}$ The effect of fluorides in stimulating bone formation and their use in the treatment of osteoporosis, ${ }^{2}$ has led to the hypothesis that water fluoridation might protect against hip fracture. Epidemiological evidence, however, associating water fluoride concentration with the incidence of hip fractures is inconsistent. Studies from the United States have suggested that fluoridation of drinking water to a level of 1 $\mathrm{mg} /$ litre has little effect on fracture incidence. ${ }^{3}$ In contrast, a two centre Finnish study ${ }^{4}$ reported a substantially lower incidence of hip fracture in a town with a water fluoride content of $1 \mathrm{mg} /$ litre as compared to that in a town with a fluoride content of $0.1 \mathrm{mg} /$ litre.

We have examined the relationship between the fluoride and calcium concentrations of drinking water and hospital discharge rates from hip fracture in 39 county districts in England and Wales.

\section{Methods}

Hospital activity analysis data on admissions with fracture of the proximal femur during 1978 to 1982 were obtained for each health region in England and Wales other than the four Thames regions which comprise London and the Home counties. In the data, a patient's residence was coded by county district. Hip fracture rates were calculated from the number of patients resident in the districts who had (a) been discharged from hospital with the diagnosis of fracture of the proximal femur (ICD 8th revision code 820), (b) been admitted as emergencies, (c) not undergone a revision of arthroplasty, and (d) were aged 45 years and over. Use of these criteria was intended to reduce the number of patients with late complications of hip fracture and those transferred between hospitals. Discharge rates were directly standardised by sex and age within five year age groups, using the 1981 population.

As part of the British Regional Heart Study, the Water Research Centre compiled data on the quality of drinking water for 253 urban areas in Britain for the period 1969 to 1973 . The calcium and fluoride content of drinking water was available for 102 of these urban areas in England and Wales. We selected 39 of these areas where the boundaries approximately matched those of a corresponding county district, in which water fluoride content did not vary throughout the area, and for which hip fracture discharge rates were available. In 28 of the 39 districts, discharge rates were based upon data for the whole five year period 1978 to 1982 . In seven, data were available for four years, while in the remaining four, discharges were only recorded for one year (appendix). Thirty of the districts did not have fluoridated water supplies, while nine had added fluoride.

The discharge rates and water composition were compared in these 39 county districts.

\section{Results}

During the study period, 4121 men and 16272 women aged 45 years and over, and resident in the 39 county districts listed in the appendix were discharged from hospital after a hip fracture. Standardised average yearly discharge rates per 1000 population in these 39 county districts ranged from 0.88 in Ipswich and Wirral to 2.30 in York. The total water fluoride content in the districts ranged from $0.005 \mathrm{mg} /$ litre in Sandwell to $0.93 \mathrm{mg} /$ litre in Birmingham. The calcium content ranged from $5.2 \mathrm{mg} /$ litre in Kirklees to $136.7 \mathrm{mg} /$ litre in Ipswich.

Figure 1 shows the relation between hip fracture discharge rate and water fluoride content in the 39 county districts. There was no association. The correlation coefficient was not statistically significant $\left(r=0 \cdot 16,95^{\circ}\right.$ confidence interval -0.16 to $0.45, p=0.34)$. The correlation remained poor when rates for men $(r=0.06$, 
Figure 1 Hip fracture discharge rate (cases per thousand population per year) and total water fluoride content (mg/litre) in 39 county districts.

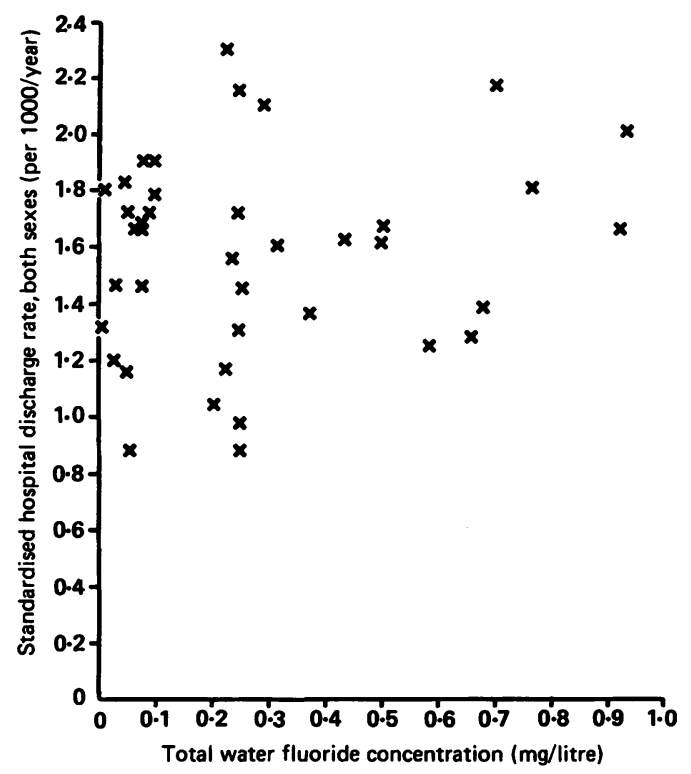

-0.26 to $0.37, p=0.70)$ and women $(r=0.17$, -0.15 to $0.46, p=0.30$ ) were analysed separately; when the analysis was restricted to the 30 county districts which did not have fluoride added to their water $(\mathrm{r}=0.01,-0.35$ to $0.37, \mathrm{p}=0.95)$; when only those 28 county districts reporting more than 50 discharges per year were included $(r=0.15,-0.24$ to $0.50, p=0.45)$; and when only those fracture cases aged less than 75 years were studied ( $\mathrm{r}=0.18,-0.14$ to $0.47, \mathrm{p}=0.27$ ).

Figure 2 shows the correlation between water calcium content and hip fracture discharge rate in the 38 of the 39 county districts for which data were available. The correlation coefficient was not statistically significant $(r=0 \cdot 16,95 \%$ confidence interval -0.17 to $0.46, p=0.35$ ).

\section{Discussion}

Our results show that the hospital discharge rates for hip fracture in the 39 county districts studied do not correlate with water fluoride or calcium content.

We have used routinely derived hospital discharge data as a means of estimating hip fracture incidence in these 39 county districts. Although almost all patients with hip fractures in this country are admitted to hospital, these data are prone to errors from three sources: diagnostic

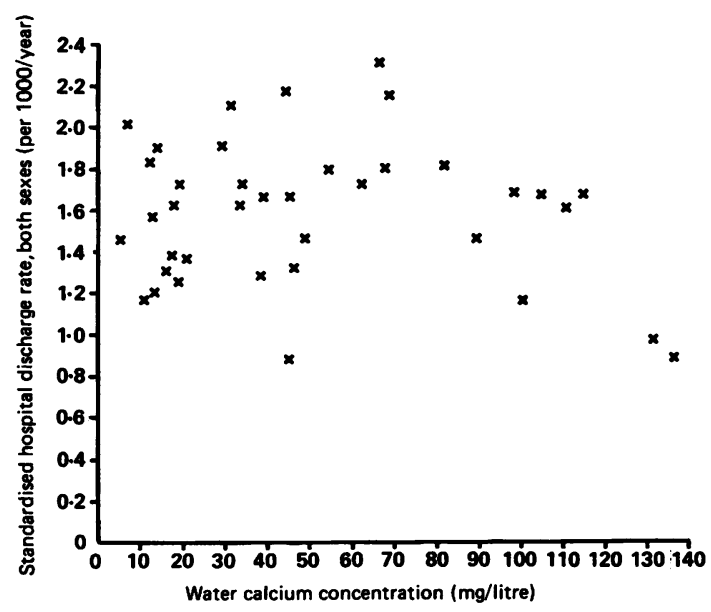

miscoding, readmission for late complications of total hip replacement, and transfer of patients between hospital. ${ }^{5}$ In order to minimise these errors we restricted entry in our study to patients admitted as emergencies who had not undergone revisions of arthroplasty. A comparison between hospital activity analysis data and a register as methods of estimating hip fracture incidence in Newcastle upon Tyne found a 7\% underestimate in the number of admissions by hospital activity analysis. ${ }^{6}$ Although the size of this discrepancy is not sufficient to influence geographic comparisons markedly, a more detailed examination of hospital activity analysis in the Northern region revealed wide variation in accuracy between hospitals. As this problem is more important in assigning rates to smaller areas, we included an analysis of only those county districts which had large numbers or recorded discharges.

The ability of fluorides to induce new bone formation and their extensive evaluation in the treatment of osteoporosis have led to epidemiological studies examining the relationship between water fluoridation and the occurrence of both osteoporosis and age related fractures. Bernstein ${ }^{8}$ showed that people living in a high fluoride area had a lower incidence of vertebral crush fractures than those living in a low fluoride area. A second study in an area with high natural fluoride content in drinking water observed a lower mortality rate from falls. ${ }^{9}$ Other studies from the United States, however, have provided little evidence for a protective effect of fluoride at levels below $2 \mathrm{mg} / \mathrm{litre}^{10-13}$ They contrast with a two centre Finnish study in which fluoridation up to $1 \mathrm{mg} /$ litre was found to be associated with a reduction in hip fracture incidence. ${ }^{4}$

Metabolic balance studies have suggested a calcium requirement of between 1 and $1.5 \mathrm{~g}$ daily to maintain positive calcium balance in middle aged and elderly Caucasian women. ${ }^{14}$ The majority of the calcium consumed is contained in dairy products, bread, puddings, cakes and biscuits. ${ }^{15}$ Our results suggest that geographic variation in the relatively small amount of calcium ingested in drinking water does not account for geographic variation in the incidence of hip fracture.

We conclude that there is no evidence of a negative correlation between hip fracture incidence and water fluoride or calcium content in 39 county districts in England and Wales. Our results suggest that water fluoridation to levels which protect against dental caries $(1 \mathrm{mg} /$ litre) does not also help to prevent hip fractures.

We thank Mr $\mathbf{P}$ Winter and Mrs $R$ Prichard for assistance with computing the hospital discharge rates and Mrs B Howells for typing the manuscript.
Figure 2 Hip fracture discharge rate (cases per thousand population per year) and water calcium content (mg/litre) in 39 county districts. 
Appendix

Water fluoride and calcium concentrations and hip fracture discharge rates in the 39 County districts.

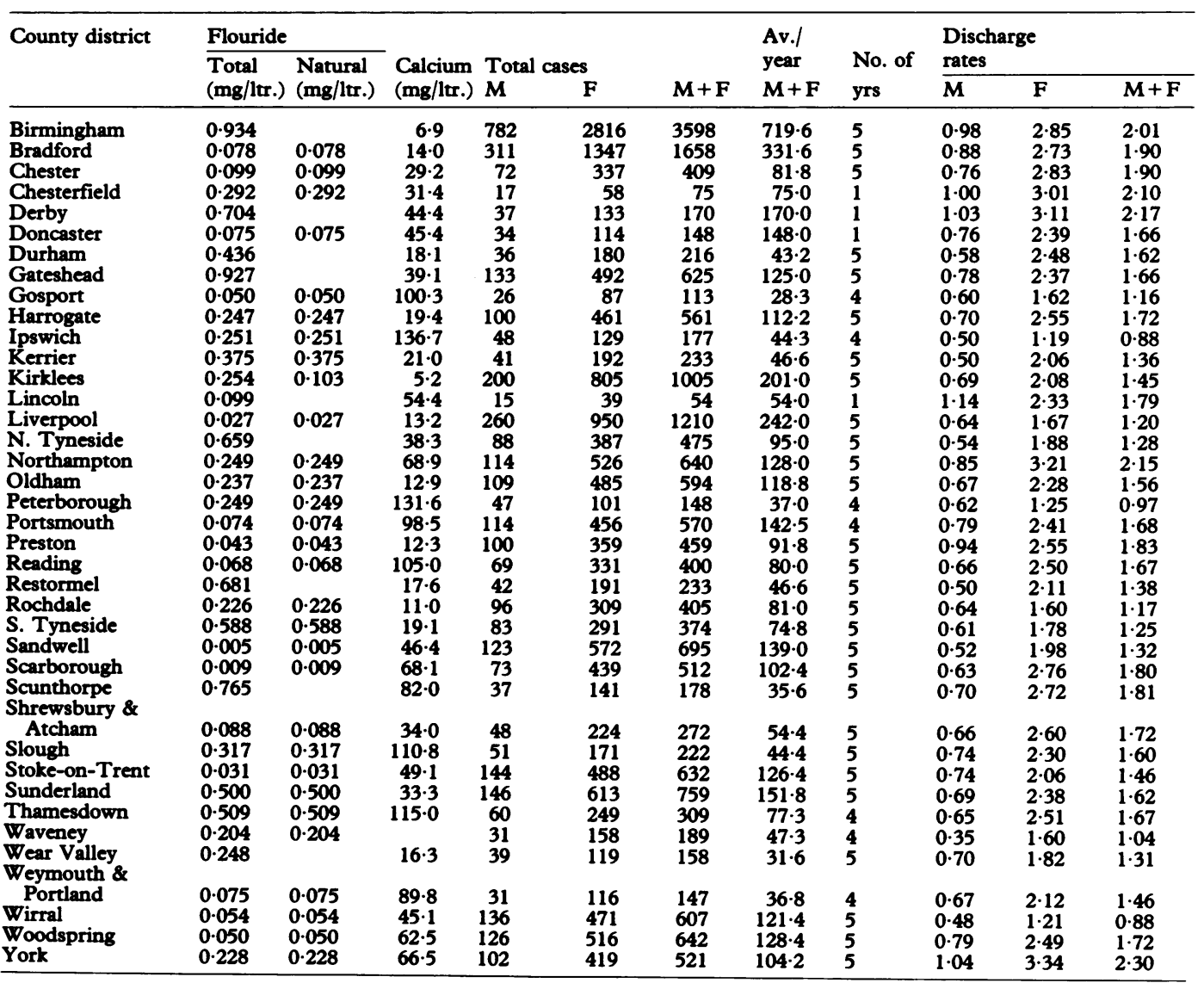

1 Cooper C, Barker DJP, Morris J, Briggs RSJ. Osteoporosis, falls and age in fracture of the proximal femur. $\mathrm{Br} M e d \mathcal{f}$ 1987; 295: 13-5.

2 Riggs BL, Baylink DJ, Kleerekoper M, Lane J, Melton LJ, Meunier PJ. Incidence of hip fractures in osteoporotic women treated with sodium fluoride. $\mathcal{Y}$ Bone Miner Res 1987; 2: 123-6.

3 Cummings SR, Kelsey JL, Nevitt MC, O'Dowd KJ. Epidemiology of osteoporosis and osteoporotic fractures. Epidemiol Rev 1985; 7: 178-208.

4 Simonen O, Laitinen O. Does fluoridation of drinking-water prevent bone fragility and osteoporosis? Lancet 1985; ii: 432-4.

5 Baker MR. An investigation into secular trends in the incidence of femoral neck fracture using hospital activity 6 Evans JG. Fractured proximal femur in Newcastle upon

7 Rees JL. Accuracy of hospital activity analysis data in estimating the incidence of proximal femoral fracture. $\mathrm{Br}$

8 Bernstein DS, Sadowsky N, Hegsted DM, Guri CD, Stare FJ. Prevalence of osteoporosis in high- and low-fluoride areas in North Dakota. $\mathcal{F} A M A$ 1966; 198: 85-90.

Iskrant AP. The etiology of fractured hips in females. $A m \mathcal{F}$ Public Health 1968; 58: 485-90.

10 Leone NC, Stevenson CA, Hilbish TF, Sosman MC. A roentgenologic study of a human population exposed to high-fluoride domestic water. A ten year study. $A m \mathcal{F}$ Roentgenol 1955; 74: 874-85.

11 Goggin JE, Haddon W, Hambly GS, Hoveland JR. Incidence of femoral fractures in postmenopausal women. Public Health Rep 1965; 80: 1005-12.

12 Korns RF. Relationship of water fluoridation to bone density in two N.Y. towns. Public Health Rep 1969; 84: 815-25.

13 Madans J, Kleinman JC, Cornoni-Huntley J. The relationship between hip fracture and water fluoridation: an analysis of national data. Am $\mathcal{F}$ Public Health 1983; 73:

14 Heaney RP, Recker RR, Saville PD. Menopausal changes in calcium balance performance. $f$ Lab Clin Med 1978; 92: 953-63.

15 Cade JE, Margetts BM. Nutrient sources in the English diet: quantitative data from three English towns. Int $\mathcal{f}$ Epidemiol 